\title{
COMPOSTOS BIOATIVOS COM CAPACIDADE ANTIOXIDANTE E ANTIMICROBIANA EM FRUTAS
}

\author{
Silvani Verruck ${ }^{1}$, Elane Schwinden Prudencio ${ }^{2}$ e Sheila Mello da Silveira ${ }^{3}$ \\ ${ }^{1}$ Universidade Federal de Santa Catarina, Departamento de Ciência e Tecnologia de Alimentos, \\ Mestre em Ciência e Tecnologia de Alimentos \\ ${ }^{2}$ Universidade Federal de Santa Catarina, Departamento de Ciência e Tecnologia de Alimentos, \\ Doutora em Ciência dos Alimentos \\ ${ }^{3}$ Instituto Federal de Educação, Ciência e Tecnologia, Centro de Ciência e Tecnologia de Alimentos \\ Doutora em Ciência dos Alimentos \\ E-mail para contato: elane.prudencio@ufsc.br
}

\begin{abstract}
RESUMO - As frutas têm reconhecida importância na alimentação humana e na prevenção de doenças, isto porque são excelentes fontes de vitaminas, minerais e fibra dietética. Além disso, possuem em sua composição ricas fontes de compostos secundários capazes de exercer benefícios à saúde de quem os consome. Entre estes compostos estão àqueles com propriedades antioxidantes e antimicrobianas. Desta forma, este trabalho de revisão apresenta as características e as vantagens dos compostos antioxidantes e antimicrobianos em frutas, a fim de servirem como alimento funcional. A revisão também fornece a base teórica necessária e alguns detalhes sobre os mecanismos oxidativos e sobre os principais métodos utilizados para a avaliação da atividade antioxidante in vitro. Assim, foram abordados alguns dos fatores que tornam a combinação de frutas e antioxidantes/antimicrobianos uma das áreas de pesquisa mais promissoras no campo da moderna ciência de vegetais.
\end{abstract}

Palavras-chave: Compostos bioativos. Compostos fenólicos. Antioxidantes. Potencial antimicrobiano.

DOI: $10.5965 / 24473650412018111$

\section{INTRODUÇÃO}

O Brasil é um país com características geográficas e climáticas favoráveis para a produção de frutas. No entanto, um grande número de frutas permanece inexplorado, apesar de seus altos valores nutricionais historicamente relatados (SCHIASSI et al., 2018). No Brasil, por exemplo, existem diferentes tipos de terras e climas que resultam em uma grande diversidade de espécies de frutas distribuídas em torno dos seis biomas (Floresta Amazônica, Caatinga, Cerrado, Mata Attântica, Pantanal e Pampa) pouco exploradas, e que representam importância econômica com potencial para contribuir com os setores alimentício, farmacêutico e agroindustrial (NERI-NUMA et al., 2018). Nos últimos anos, foi observado um aumento nos estudos com frutas, bem como o desenvolvimento de 
Recebido em:

$11 / 07 / 2018$

Aceito em:

$29 / 11 / 2018$

novos produtos alimentícios com base nelas, porém informações sobre as características químicas e valor nutricional das frutas brasileiras ainda precisam ser mais exploradas (SCHIASSI et al., 2018). Contudo, espécies frutíferas não amplamente consumidas estão sendo empregadas como alternativa às espécies tradicionais (KREMER-SADLIK et al., 2015). Isso porque as frutas podem se tornar uma fonte inesgotável de recursos nutricionais, uma vez que são uma fonte potencial de compostos bioativos, como os compostos fenólicos, vitaminas, carotenóides e minerais, e reconhecidas como fontes de fibras alimentares solúveis e insolúveis, que desempenham um papel importante na alimentação (SCHIASSI et al., 2018). Habibi e Ramezanian (2017) afirmaram que o alto consumo de frutas é associado a uma menor incidência de doenças como câncer, disfunções cardiovasculares, inflamação, aterosclerose, declínio do sistema imunológico; desempenhando papel importante na atividade antiviral e na prevenção de processos neurodegenerativos. Fang, Meng e Min (2018) confirmaram que a prevenção de doenças degenerativas está realacionada também ao consumo de frutas que apresentam elevada capacidade antioxidante. Jiao et al. (2018) reforçam que o estudo de compostos associados à capacidade antioxidante são de grande interesse porque são capazes de absorver radicais livres e assim inibir a cadeia de iniciação ou até mesmo interromper a cadeia de propagação das reações oxidativas, causadas pelos radicais livres no organismo humano. Dentre estes compostos com atividade antioxidante encontram-se os fenólicos. Cabe ressaltar que os compostos fenólicos em frutas são naturais e, portanto, mais aceitáveis para os consumidores do que os antioxidantes sintéticos. Há um interesse crescente na descoberta e identificação de compostos fenólicos que ocorrem naturalmente em frutas, com o objetivo de encontrar novas e promissoras fontes de antioxidantes para a saúde humana (LIU et al., 2018). Assim, o objetivo deste trabalho foi apresentar as características e as vantagens dos compostos antioxidantes em frutas, bem como dos antimicrobianos, incluindo os mecanismos oxidativos e os principais métodos utilizados para a avaliação da atividade antioxidante in vitro.

\section{CAPACIDADE ANTIOXIDANTE E ANTIMICROBIANA DE COMPOSTOS BIOATIVOS DE FRUTAS}

Vuotto et al. (2000) avaliaram a atividade antioxidante e antimicrobiana do extrato aquoso da fruta popularmente conhecida como goiaba-serrana, também da família Myrtaceae e encontrou forte atividade contra Pseudomonas aeruginosa, Enterobacter aerogenes e E. cloacae. Cardoso et al. (2010) em seu estudo com extratos hexânicos de frutos de Campomanesia pubensces e $C$. adamantium encontraram valores de concentração mínima inibitória entre 5 e $20 \mu \mathrm{g} \mathrm{mL}^{-1}$ para duas bactérias Gram-positivas (Staphylococcus aureus e Pseudomonas aeruginosa), duas bactérias Gramnegativas (Escherichia coli e Salmonella Setúbal), e duas leveduras (Saccharomyces cerevisiae e Candida albicans). Onivogui et al. (2016) encontrou atividades antibacterianas e antifúngicas dos extratos em metanol e etanol da fruta Anisophyllea laurina que exibiram potente atividade inibitória do crescimento contra Aeromonas hydrophila, Bacillus subtilis, Escherichia coli O157:H7, Pseudomonas aeruginosa, Salmonella typhimurium e Staphylococcus aureus ATCC 6538, com valores mínimos de concentração inibitória variando de 125 a $250 \mu \mathrm{g} / \mathrm{mL}$. No entanto, o extrato da semente desta planta apresentou maior atividade contra Aspergillus niger e Candida albicans, com um valor mínimo de concentração inibitória de $500 \mu \mathrm{g} / \mathrm{mL}$ (ONIVOGUI et al., 2016). Pereira et al. (2018) citaram que o extrato de frutos do Araçá demonstrou atividade antibacteriana in vitro contra 
Recebido em:

$11 / 07 / 2018$

Aceito em:

$29 / 11 / 2018$

Salmonella enteritidis, freqüentemente descrito na literatura sobre a ocorrência de toxinfecções em humanos. Os extratos apresentaram concentração inibitória mínima a 5\%, sendo que os extratos com maiores concentrações de metabólitos secundários foram mais efetivos contra a proliferação bacteriana. Atividade intermediária foi reportada para o araçá contra Bacillus subtilis e Staphylococcus aureus (PEREIRA et al., 2018). Atividade antibacteria para a Campomanesia adamantium foi encontrada por Sá et al. (2018). Estes autores, bem como Pereira et al. (2018) concluiram que compostos secundários bioativos como, por exemplo, os compostos fenólicos com atividades antioxidantes seriam responsáveis pela ação contra a atividade antimicrobiana.

Taiz e Zeiger (2004) verificaram que frutas produzem grande variedade de compostos orgânicos secundários que parecem não ter função direta no seu crescimento e desenvolvimento, sendo que estes metabólitos secundários diferem dos metabólitos primários, ou seja, de aminoácidos, ácidos nucléicos, açúcares e lipídeos. No entanto, os metabólitos secundários têm a função de proteger as plantas contra os herbívoros e contra a infecção por micro-organismos patogênicos. Agem como atrativos (odor, cor ou sabor) para animais e atuam como agentes na competição planta com planta e nas simbioses plantas e micro-organismos. Estes compostos secundários são divididos em três grupos quimicamente distintos compreendendo terpenos, compostos fenólicos e compostos nitrogenados. A Figura 1 mostra, de forma simplificada, as rotas envolvidas na biossíntese dos metabólitos secundários e suas interconexões com o metabolismo primário (TAIZ; ZEIGER, 2004). A Figura 2 aborda resumidamente as principais classes de fitoquímicos. De acordo com MartínezNavarrete, Vidal e Lahuerta (2008) os fitoquímicos presentes nas frutas são em sua maioria da classe dos compostos fenólicos (flavonoides) e terpênicos (carotenoides).

\subsection{Compostos Fenólicos}

As plantas produzem uma grande diversidade de produtos secundários que contêm um grupo fenol - um grupo hidroxila funcional em um anel aromático (LIU et al., 2018). Tais substâncias são classificadas como compostos fenólicos. Os fenólicos vegetais constituem um grupo quimicamente heterogêneo, com aproximadamente 10.000 compostos, sendo que alguns são solúveis apenas em solventes orgânicos, outros são ácidos carboxílicos e glicosídeos solúveis em água e há, ainda, aqueles que são grandes polímeros insolúveis (TAIZ; ZEIGER, 2004). Eles estão quase universalmente presentes nas plantas e são conhecidos por acumularem-se em todas as partes do vegetal: raízes, caules, folhas, flores e frutos (LIU et al., 2018).

Devido à sua diversidade química, os compostos fenólicos apresentam uma variedade de funções nos vegetais. Muitos agem como compostos de defesa contra herbívoros e patógenos, enquanto outros têm função como atrativo de polinizadores ou dispersores de frutos, na proteção contra a radiação ultravioleta, no suporte mecânico ou reduzindo o crescimento de plantas competidoras adjacentes (TAIZ; ZEIGER, 2004). Os compostos fenólicos podem ser classificados de acordo com o tipo do esqueleto principal, como apresentado na Tabela 1, onde C6 representa o anel benzênico e CX representa a cadeia substituinte com $\mathrm{X}$ átomos de carbono. A maior parte dos compostos fenólicos não é encontrada no estado livre na natureza, mas na forma de ésteres ou de heterosídeos sendo, portanto, solúveis em água e em solventes orgânicos polares, porém não são muito reativos quimicamente. Assim, estes compostos, possuem em geral características ácidas, e podem ser isolados através da sua solubilidade em soluções fracamente básicas. Estes compostos 
Recebido em:

$11 / 07 / 2018$

Aceito em:

$29 / 11 / 2018$

também podem formar pontes de hidrogênio e estas podem ser tanto intramoleculares como intermoleculares. Uma característica importante é a propriedade de complexação dos fenóis com metais. Por serem compostos aromáticos, apresentam intensa absorção na região do UV, são facilmente oxidáveis, tanto através de enzimas vegetais específicas quanto por influência de metais (como ferro e manganês), da luz e do calor, ou em meio alcalino, acarretando o escurecimento de suas soluções ou dos compostos isolados (CARVALHO; GOSMANN; SCHENKEL, 2004 apud SIMÕES et al., 2004).

Figura 1 - Principal rota da biossíntese de metabólitos secundários e suas interações com o metabolismo primário

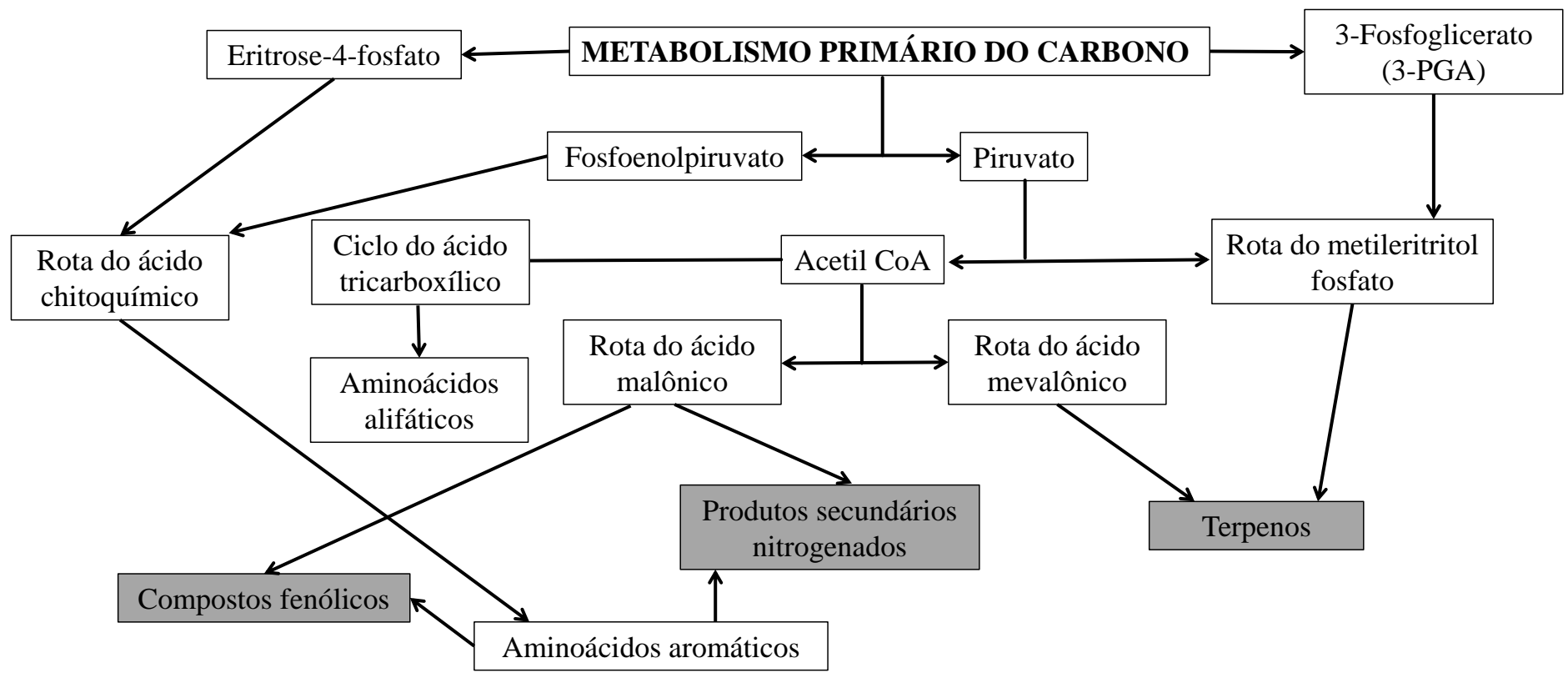

Fonte: Adaptado de Taiz e Zeiger (2004). 
Recebido em:

$11 / 07 / 2018$

Aceito em:

$29 / 11 / 2018$

Figura 2 - Classificação dos fitoquímicos

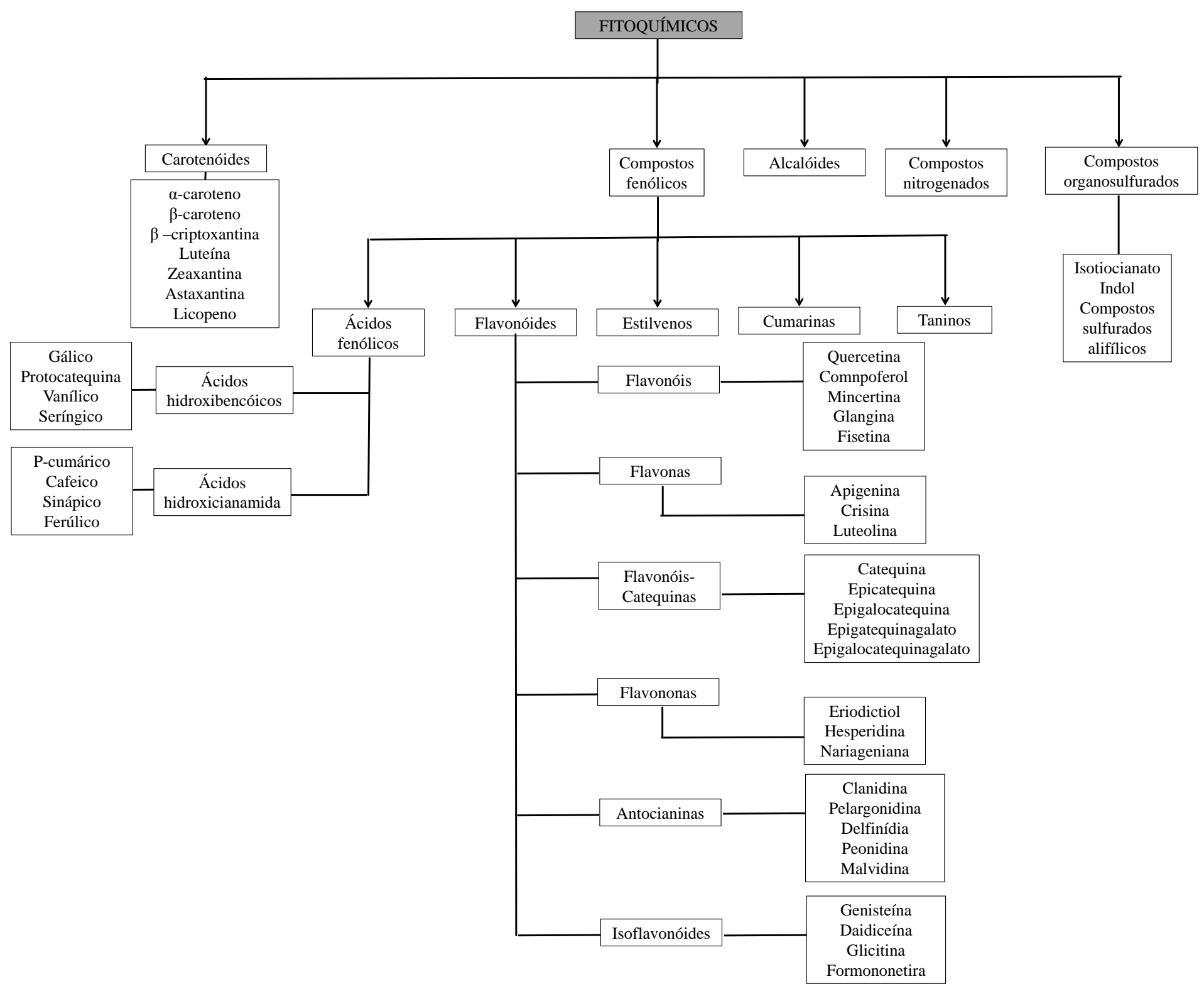

Fonte: Adaptado de Liu (2004). 
Recebido em:

$11 / 07 / 2018$

Aceito em:

$29 / 11 / 2018$

Tabela 1 - Classificação dos compostos fenólicos de acordo com a estrutura básica

\begin{tabular}{ll}
\hline Estrutura básica & Classe de compostos fenólicos \\
\hline C6 & Fenóis simples, benzoquinonas \\
C6-C1 & Ácidos fenólicos \\
C6-C2 & Acetofenonas e ácidos fenilacéticos \\
C6-C3 & Fenilpropanóides: ácidos cinâmicos e compostos análogos, \\
& fenilpropenos, cumarinas, isocumarinas e cromonas \\
C6-C4 & Naftoquinonas \\
C6-C1-C6 & Xantonas \\
C6-C2-C6 & Estilbenos, antraquinonas \\
C6-C3-C6 & Flavonoides e isoflavonoides \\
$(\text { C6-C3 })_{2}$ & Lignanas \\
$(\text { C6-C3-C6 })_{2}$ & Diflavonoides \\
$(\text { C6 })_{n}$ & Melaninas vegetais \\
$(\text { C6-C3 })_{\mathrm{n}}$ & Ligninas \\
$(\text { C6-C1 })_{n}$ & Taninos hidrolisáveis \\
$(\text { C6-C3-C6 })_{n}$ & Taninos condensados \\
\hline
\end{tabular}

Fonte: Carvalho, Gosmann e Schenkel (2004 apud SIMÕES et al., 2004)

Os flavonoides constituem a maior classe de fenólicos vegetais. O esqueleto básico de carbono dos flavonoides contém 15 carbonos organizados em dois anéis aromáticos, conectados por uma ponte de três carbonos. Os tipos diferentes de flavonoides desempenham funções diversas nos vegetais, incluindo pigmentação e defesa (TAIZ; ZEIGER, 2004). São conhecidos por volta de 4.200 flavonoides diferentes que se apresentam frequentemente oxigenados, sendo que um grande número está conjugado com açúcar. Na Tabela 2 estão apresentadas as principais classes de flavonoides e um resumo de suas características mais importantes. Os flavonoides encontrados nas folhas podem ser diferentes daqueles presentes nas flores, nos caules ou ramos, raízes ou frutos. O mesmo composto ainda pode ocorrer em diferentes concentrações, dependendo da parte vegetal em que se encontra. Pesquisas sugerem que alguns flavonoides são responsáveis por ação antitumoral considerável, podendo ainda agir como antivirais, anti-hemorrágicos, hormonais, anti-inflamatórios, antimicrobianos e antioxidantes (ZUANAZZI; MONTANHA, 2004 apud SIMÕES et al., 2004).

Os flavonoides e outros derivados fenólicos são conhecidos por atuarem na captura e neutralização de espécies oxidantes como o radical hidroxila, o ânion superóxido $\left(\mathrm{O}^{2-}\right)$ ou o radical peróxido, atuando por sinergismo com outros antioxidantes como as vitaminas C e E. Alguns flavonoides são capazes de se ligar a íons metálicos, impedindo-os de atuarem como catalisadores na produção de radicais livres. Esta atividade é o resultado de um conjunto de propriedades, tais como atividade quelante de ferro, atividade sequestrante de radicais livres, inibição das enzimas cicloxigenase, lipoxigenase, NADPH-oxidase, xantina-oxidase e fosfolipase, e estimulação de enzimas com atividade antioxidante como a catalase e a superóxido-dismutase. Assim, os flavonoides podem interferir nas reações de propagação e formação de radicais livres (TRUEBA; SANCHEZ, 2001). Cushnie e Lamb (2011) relatam os seis grupos de flavonoides (flavonas, flavonóis, chaconas, 
Recebido em:

$11 / 07 / 2018$

Aceito em:

$29 / 11 / 2018$

flavon-3-ol, flavononas e protoantocianidinas) mais estudados em relação à atividade antimicrobiana contra várias espécies de bactérias patogênicas.

Tabela 2 - Classes de flavonoides e algumas características conhecidas

\begin{tabular}{|c|c|c|}
\hline Classes & $\begin{array}{l}\text { Número aproximado de } \\
\text { estruturas conhecidas }\end{array}$ & Características \\
\hline $\begin{array}{l}\text { Flavonas, flavonóis e seus } O- \\
\text { heterosídeos }\end{array}$ & 1660 & $\begin{array}{l}\text { Co-pigmentação em flores; protetor } \\
\text { contra raios UV nas folhas }\end{array}$ \\
\hline$C$-heterosídeos & 303 & \\
\hline Antocianos & 256 & Pigmentação do vermelho até o azu] \\
\hline Chalconas & 197 & Pigmentação amarela \\
\hline Auronas & 29 & Pigmentação amarela \\
\hline Di-hidro-flavonóis & 110 & $\begin{array}{l}\text { Estão presentes em tecidos de } \\
\text { madeiras }\end{array}$ \\
\hline Flavanonas & 319 & Podem apresentar sabor amargo \\
\hline Di-hidro-chalconas & 71 & Podem apresentar sabor amargo \\
\hline $\begin{array}{l}\text { Flavanas, leucoantocianidinas e } \\
\text { proantocianidinas }\end{array}$ & 309 & $\begin{array}{l}\text { Substâncias adstringentes com } \\
\text { propriedades tanantes }\end{array}$ \\
\hline Isoflavonoides & 630 & $\begin{array}{l}\text { Propriedades estrogênicas e/ou } \\
\text { antifúngicas }\end{array}$ \\
\hline Neoflavonoides & 70 & \\
\hline Biflavonoides & 134 & Propriedades antifúngicas \\
\hline Outras estruturas & 100 & \\
\hline
\end{tabular}

Fonte: Zuanazzi e Montanha (2004 apud SIMÕES et al., 2004)

\subsection{Terpenos}

Entre os compostos terpênicos mais encontrados em frutas então os carotenoides (MARTÍNEZNAVARRETE; VIDAL; LAHUERTA, 2008). A estrutura básica dos carotenoides consiste em oito unidades de isopreno unidas de tal forma que ocorre uma reversão na parte central da molécula e os dois grupos metílicos centrais ficam separados por três carbonos. Já foram identificados mais de 600 carotenoides, os quais podem ser subdivididos em dois grupos principais: os carotenos (compostos contituídos por carbono e hidrogênio) e as xantofilas (derivados obtidos por oxidação dos carotenos com formação dos grupos hidroxila, metoxila, carboxila, cetona). Alguns carotenoides apresentam propriedades antioxidantes e são conhecidos por reagir com o oxigênio singlete e, portanto, proteger as células dos radicais livres (RIBEIRO; SERAVALLI, 2007) e por capturar radicais peroxil mediante transferência de elétrons ou sequestro de átomos de hidrogênio (RUFINO, 2008). Dentre os compostos bioativos, os terpenos constituem a maior classe de produtos secundários (CHANDRASEKARA; SHAHIDI, 2018). As diversas substâncias desta classe são, em geral, insolúveis em água e sintetizados a partir de acetil CoA ou de intermediários glicolíticos. Todos os terpenos derivam-se da união de unidades pentacarbonadas que apresentam um esqueleto ramificado de isopentano, e são classificados pelo número de unidades de $\mathrm{C}_{5}$ que possuem. Os terpenos de 10 carbonos, que têm duas unidades $\mathrm{C}_{5}$, são designados monoterpenos; os de 15 carbonos, que têm três 
Recebido em:

$11 / 07 / 2018$

Aceito em:

$29 / 11 / 2018$

unidades $\mathrm{C}_{5}$ são os sesquiterpenos e os terpenos de 20 carbonos, que têm quatro unidades $\mathrm{C}_{5}$ são os diterpenos. Os maiores terpenos incluem os triterpenos (30 carbonos), tetraterpenos (40 carbonos) e politerpenóides $\left(\left[\mathrm{C}_{5}\right]_{\mathrm{n}}\right.$ carbonos, onde $\left.\mathrm{n}>8\right)$. Estes compostos são sintetizados a partir de metabólitos primários (TAIZ; ZEIGER, 2004).

\section{MECANISMOS OXIDATIVOS}

Todos os organismos biológicos aeróbios produzem radicais livres a partir do oxigênio triplete birradical $\left(\mathrm{O}_{2}\right)$, os quais reagem com diferentes macromoléculas biológicas, formando outros radicais livres (CHITARRA; CHITARRA, 2005). São classificados como radicais livres as moléculas orgânicas e inorgânicas e os átomos que contêm um ou mais elétrons não pareados com existência independente (LUNA; ESTÉVEZ, 2018). As espécies de oxigênio reativo são produzidas durante o curso normal do metabolismo e reagem com as estruturas orgânicas estáveis adjacentes (lipídeos e proteínas das membranas celulares, aminoácidos), retirando delas um elétron, o qual irá se parear com o seu elétron isolado. Desta forma, tem início a peroxidação de lipídeos e a agregação de proteínas com efeitos danosos às membranas, vazamentos de eletrólitos, distúrbios metabólicos, perda das funções celulares e consequente morte das células e tecidos (CHITARRA; CHITARRA, 2005).

O estresse oxidativo ocorre em situações em que há desequilíbrio entre os níveis de antioxidantes e de pró-oxidantes, com o predomínio destes últimos. Assim, a diminuição dos sistemas de defesa antioxidante ou o aumento da geração de espécies oxidantes, radicalares ou não, pode resultar em lesões oxidativas em macromoléculas e diversas estruturas celulares que, se não forem reparadas, alterarão a funcionalidade de células, tecidos e órgãos (ABDALLA; FAINE, 2008 apud OGA; CAMARGO; BATISTUZZO, 2008).

Os radicais livres podem ser formados pela perda ou adição de um único elétron a um composto não radicalar. O elétron livre, que caracteriza o radical livre, pode estar centrado em um átomo de oxigênio, nitrogênio, carbono ou enxofre. A toxicidade do oxigênio decorre da formação destas espécies reativas que podem interagir com diversas biomoléculas e lesar diferentes estruturas celulares. De maneira geral, a denominação radical livre refere-se a uma molécula ou átomo muito reativo, que tem número ímpar de elétrons em sua última camada eletrônica. É este não emparelhamento de elétrons da última camada que confere alta reatividade a esses átomos ou moléculas (ABDALLA; FAINE, 2008 apud OGA; CAMARGO; BATISTUZZO, 2008).

São tipos de radicais livres o oxigênio singlete, radical superóxido, radical hidroxila, óxido nítrico, peroxinitrito e radical semiquinona (BIANCHI; ANTUNES, 1999). As reações radicalares ocorrem em três etapas denominadas de iniciação, propagação e terminação. Salvo o começo da reação, as três etapas desenvolvem-se simultaneamente. Nas reações de iniciação, formam-se radicais livres a partir dos ácidos graxos insaturados, que se combina com o oxigênio, produzindo peróxidos lipídicos; nas reações de propagação, acumulam-se os peróxidos, e é nessa etapa que se oxida a maioria dos lipídeos insaturados; nas reações de terminação, os radicais livres procedentes da decomposição dos peróxidos lipídicos associam-se, formando compostos não radicais de baixa massa molar (aldeídos, cetonas, lactonas, ácidos graxos de cadeia curta, entre outros), responsáveis pelo odor de ranço (PEREDA et al., 2005). 
Recebido em:

$11 / 07 / 2018$

Aceito em:

$29 / 11 / 2018$

\subsection{Antioxidantes}

Uma substância antioxidante pode ser definida como uma substância química que inibe o processo de oxidação, ou qualquer substância que, quando presente em baixa concentração, comparada à do substrato oxidável, diminui ou inibe significativamente a oxidação daquele substrato. Do ponto de vista biológico, pode-se definir antioxidantes como compostos que protegem sistemas biológicos contra os efeitos danosos de reações que promovem a oxidação de macromoléculas ou estruturas celulares (ABDALLA; FAINE, 2008 apud OGA; CAMARGO; BATISTUZZO, 2008). Podem ser citados as vitaminas $\mathrm{E}$ e $\mathrm{C}$, os minerais $(\mathrm{Cu}, \mathrm{Sn}, \mathrm{Zn}, \mathrm{Mg}, \mathrm{Fe})$, os carotenoides e os compostos fenólicos entre os principais antioxidantes consumidos através dos alimentos (PEREIRA, 2011). O consumo de antioxidantes naturais, como os compostos fenólicos presentes na maioria das plantas que inibem a formação de radicais livres, também chamados de substâncias reativas, tem sido associado a uma menor incidência de doenças relacionadas com o estresse oxidativo (SINGH et al., 2018). Já a vitamina E ( $\alpha$-tocoferol) consumida, é transportada na corrente sanguínea pelos componentes lipoproteicos e, em conjunto com as ubiquinonas, evitam a peroxidação lipídica. A vitamina $\mathrm{C}$ atua extinguindo o oxigênio singlete, também evitando a peroxidação lipídica e o $\beta$ caroteno atua na prevenção ou retardo das reações oxidativas que, ao longo do tempo, conduzem ao desenvolvimento de doenças degenerativas (CHITARRA; CHITARRA, 2005).

A importância concernente ao desempenho dos antioxidantes depende dos fatores tipos de radicais livres formados; onde e como são gerados esses radicais; análise e métodos para a identificação dos danos, e doses ideais para obter proteção. Assim, é perfeitamente possível que um antioxidante atue como protetor em determinado sistema, mas que falhe na proteção, ou mesmo que aumente as lesões induzidas em outros sistemas ou tecidos (SINGH et al., 2018).

Os antioxidantes atuam em diferentes níveis na proteção dos organismos. O primeiro mecanismo de defesa contra os radicais livres é impedir a sua formação, principalmente pela inibição das reações em cadeia com o ferro e o cobre. Os antioxidantes são capazes de interceptar os radicais livres gerados pelo metabolismo celular ou por fontes exógenas, impedindo o ataque sobre os lipídeos, os aminoácidos das proteínas, a dupla ligação dos ácidos graxos poli-insaturados e as bases do DNA, evitando a formação de lesões e perda da integridade celular. Os antioxidantes obtidos da dieta, tais como as vitaminas $\mathrm{C}, \mathrm{E}$ e $\mathrm{A}$, os flavonoides e carotenoides são extremamente importantes na interceptação dos radicais livres. Outro mecanismo de proteção é o reparo das lesões causadas pelos radicais. Esse processo está relacionado com a remoção de danos da molécula de DNA e a reconstituição das membranas celulares danificadas. Em algumas situações pode ocorrer uma adaptação do organismo em resposta à geração desses radicais com o aumento da síntese de enzimas antioxidantes (BIANCHI; ANTUNES, 1999).

\subsection{Métodos para avaliação da atividade antioxidante in vitro}

O crescente interesse pelos efeitos benéficos dos antioxidantes à saúde tem feito com que seja desenvolvida uma grande quantidade de métodos para determinar a atividade antioxidante dos extratos de alimentos (RUFINO, 2008). A literatura descreve vários métodos para a determinação de antioxidantes in vitro em extratos de plantas e substâncias puras. Dentre as mais utilizadas estão a capacidade de sequestro do radical $\mathrm{DPPH}^{\bullet}$ (2,2-Difenil-1-picrilhidrazil), a capacidade de sequestro do radical $\mathrm{ABTS}^{\bullet+}$ 2,2’-azinobis(3-etilbenzotiazolina-6-ácido sulfônico), a atividade antioxidante total 
Recebido em:

$11 / 07 / 2018$

Aceito em:

$29 / 11 / 2018$

pelo método do fosfomolibdênio, poder antioxidante de redução do ferro (FRAP) e Sistema $\beta$ Caroteno/Ácido Linoleico (LIU, 2010; RUFINO et al, 2007; RUFINO, 2008). Os seguintes principais métodos são empregados na determinação da atividade antioxidante in vitro:

(a) Determinação de Compostos Fenólicos: O método de Folin-Ciocalteu não é exatamente um método para determinação de atividade antioxidante, mas de determinação de compostos fenólicos totais. Porém, devido ao importante papel destes compostos, em muitos trabalhos são referidos como um método de determinação de compostos antioxidantes, apesar de ser apenas um indicador (RUFINO, 2008).

O método de Folin-Ciocalteu é um dos ensaios mais antigos usados para a determinação de compostos fenólicos totais (SINGLETON; ORTHOFER; LAMUELA-RAVENTOS, 1999). O reagente ativo consiste de uma solução ácida amarela contendo um complexo polimérico de íons formados pelos heteropoliácidos fosfomolibídico e fosfotúngstico. Este reagente oxida os fenolatos e assim os heteropoliácidos tornam-se parcialmente reduzidos do estado de valência +6 a uma mistura de +6 e +5 , resultando na produção do complexo azul molibdênio-tungstênio (SINGLETON; ROSSI, 1965). Esta reação tem uma alta absortividade próxima a 750nm. Normalmente os fenólicos determinados por este método são expressos em equivalente de ácido gálico (ROGINSKY; LISSI, 2005).

(b) Sequestro do radical DPPH (2,2-difenil-1-picrilhidrazila): O método DPPH consiste na redução do radical DPPH• (2,2-difenil-1-picrilhidrazila) de coloração púrpura que absorve a $515 \mathrm{~nm}$, relativamente estável em solução alcoólica na presença de antioxidantes doadores de hidrogênio. $\mathrm{O}$ DPPH, ao receber um elétron ou um radical hidrogênio, muda sua coloração de violeta para violetaclaro com traços de amarelo, ficando estável e com o desaparecimento da absorção que pode ser avaliada pelo decréscimo da absorbância. A ação antioxidante é expressa em \% e pela quantidade de antioxidante necessária para decrescer a concentração inicial de DPPH em 50\%, chamada de $\mathrm{IC}_{50}$. Quanto maior o consumo de DPPH por uma amostra, menor será a sua $\mathrm{IC}_{50}$ e maior a sua atividade antioxidante (BRAND-WILLIANS; CURVELIER; BERSET, 1995; LIU, 2010; MOLYNEUX, 2004; SOUSA et al., 2007).

(c) Capacidade de sequestro do radical $\mathrm{ABTS}^{\bullet+}$ 2,2'- azinobis(3-etilbenzotiazolina-6-ácido sulfônico): O método $\mathrm{ABTS}^{\bullet+}$ 2,2’- azinobis(3-etilbenzotiazolina-6-ácido sulfônico) baseia-se em uma reação por transferência de elétrons, no qual avalia-se a capacidade antioxidante de capturar o cátion radical $\mathrm{ABTS}^{\circ+}$. Esta captura produz um decréscimo na absorbância a $734 \mathrm{~nm}$. O decréscimo produzido pelo Trolox (análogo hidrossolúvel da vitamina E) é comparado ao produzido pelos antioxidantes que se está analisando. A curva gerada pela inibição da absorbância é calculada, sendo que os resultados são interpolados na curva de calibração e expressos em atividade antioxidante equivalente a $1 \mathrm{mM}$ de trolox. O radical ABTS é produzido quimicamente com o persulfato de potássio (RE et al., 1999; RUFINO et al, 2007).

(d) Atividade antioxidante total pelo método do fosfomolibdênio: De acordo com Prieto, Pineda e Aguilar (1999), o método do fosfomolibdênio é rotineiramente utilizado em laboratórios para avaliar a capacidade antioxidante total de extratos de plantas. Esse método baseia-se na redução do $\mathrm{Mo}(\mathrm{VI})$ em $\mathrm{Mo}(\mathrm{V})$ e subsequente formação do complexo fosfato de $\mathrm{Mo}(\mathrm{V})$. Essa determinação espectrofotométrica apresenta absorção máxima a $695 \mathrm{~nm}$.

(e) Poder antioxidante de redução do ferro (FRAP): A técnica de redução do ferro (redução do $\mathrm{Fe}^{3+}$ ) é frequentemente usada como um indicador de atividade de doação de elétron, o qual é um importante 
Recebido em:

$11 / 07 / 2018$

Aceito em:

$29 / 11 / 2018$

mecanismo de ação de antioxidantes fenólicos e pode ser fortemente correlacionada com outras propriedades antioxidantes (DORMAN et al., 2003). Neste método, a coloração amarela da solução teste muda para várias tonalidades de verde e azul, dependendo do poder de redução de cada composto. A presença de redutores (antioxidantes) causa a redução do complexo $\mathrm{Fe}^{3+} /$ ferrocianeto $^{2}$ para a forma ferrosa $\left(\mathrm{Fe}^{2+}\right)$. A medida espectrofotométrica em comprimento de onda de $700 \mathrm{~nm}$ é utilizada para avaliar a concentração de Fe ${ }^{2+}$ (HARNAFI; AMRANI, 2008).

(f) Sistema $\beta$-Caroteno/Ácido Linoleico: O método de co-oxidação do sistema $\beta$-caroteno/ácido linoleico, determina a capacidade que um composto tem em proteger os lipídeos da oxidação e baseia-se na descoloração do $\beta$-caroteno que absorve a $470 \mathrm{~nm}$, em uma emulsão aquosa saturada de oxigênio, induzida pelos produtos da oxidação do ácido linoleico. A utilização de antioxidantes retarda a queda da absorbância do $\beta$-caroteno, protegendo os substratos lipídicos da oxidação. A atividade antioxidante (\%) neste sistema é calculada em relação a $100 \%$ da oxidação da amostra controle (sem antioxidante) (DUARTE-ALMEIDA et al., 2006).

\section{CONCLUSÕES E PERSPECTIVAS}

Foram abordados neste trabalho, alguns dos fatores que tornam a combinação de frutas e antioxidantes/antimicrobianos uma das áreas de pesquisa mais promissoras em relação aos vegetais. No entanto, o Brasil possui ampla quantidade de frutas nativas que ainda são pouco exploradas, que vêm recebendo muita atenção devido ao aumento de seu potencial de mercado, com foco na diversificação da oferta aos consumidores. Os benefícios funcionais desta matriz alimentar permanecem inexplorados pela área, apresentando grande potencialidade para o setor. Assim, mais estudos também são necessários para investigar os efeitos dos compostos antioxidantes e antimicrobianos em frutas em relação à saúde dos consumidores.

\section{REFERÊNCIAS}

ABDALLA, D. S. P.; FAINE, L. A. Radicais livres e antioxidantes. In: OGA, S; CAMARGO, M. M. A.; BATISTUZZO, J. A. O. Fundamentos de Toxicologia. $3^{\text {a }}$ edição. São Paulo:Atheneu Editora, p. 37-58, 2008.

BIANCHI M. L. P.; ANTUNES, L. M. G. Radicais livres e os principais antioxidantes da dieta. Revista de Nutrição, v. 12. n. 2, p. 123-130, 1999.

BRAND-WILLIANS, W.; CUVELIER, M. E.; BERSET, C. Use of a free radical method to evaluate antioxidant activity. Food Science and Technology, v. 28, n. 1, p. 25-30, 1995.

CARVAlHO, J. C. T.; GOSMANN, G.; SCHENKEL, E. P. Compostos fenólicos simples e heterosídicos. In: SIMÕES, C. M. O. et al.. Farmacognosia: da planta ao medicamento. 5. ed. Florianópolis: UFSC, 2004. 1102 p. 
CHANDRASEKARA, A.; SHAHIDI, F. Herbal beverages: bioactive compounds and their role in disease risk reduction - a review. Journal of Traditional and Complementary Medicine, $\mathrm{v}$. 8, p. 451-458, 2018.

CHITARRA, M. I. F.; CHITARRA, A. B. Pós-colheita de frutos e hortaliças: fisiologia e manuseio. 2. ed. Lavras: UFLA, 2005. 785 p.

CUSHNIE, T. P. T.; LAMB, A. J. Recent advances in understanding the antibacterial properties of flavonoids. International Journal of Antimicrobial Agents, v. 38, p. 99- 107, 2011.

DORMAN, H. J. D. et al. Characterization of the antioxidant properties of de-odourised aqueous extracts from selected Lamiaceae herbs. Food Chemistry, v. 83, n. 2, p. 255-262, 2003.

DUARTE-ALMEIDA, J. M. et al. Avaliação da atividade antioxidante utilizando sistema $\beta$-caroteno/ ácido linoléico e método de sequestro de radicais DPPH•. Ciência e Tecnolologia de Alimentos, v. 26, n. 2, p. 446-452, 2006.

FANG, L.; MENG, W.; MIN, W. Phenolic compounds and antioxidant activities of flowers, leaves and fruits of five crabapple cultivars (Malus Mill. species). Scientia Horticulturae, v. 235, p. 460-467, 2018.

HABIBI, F.; RAMEZANIAN, A. Vacuum infiltration of putrescine enhances bioactive compounds and maintains quality of blood orange during cold storage. Food Chemistry, v. 227, p. 1-8, 2017.

HARNAFI, H.; AMRANI, S. Spectrophotometric methods for determination of plant polyphenols content and their antioxidant activity assessment: an overview. Pharmacognosy reviews, v. 2, n.3, p. 20-22, 2008.

JIAO, Y. et al. Assessment of phenolic contributors to antioxidant activity of new kiwifruit cultivars using cyclic voltammetry combined with HPPLC. Food Chemistry, v. 268, p. 77-85, 2018.

KREMER-SADLIK, T. et al. Eating fruits and vegetables: an ethnographic study of american and french family dinners. Appetite, v. 89, p. 84-92, 2015.

LIU, R. H. Potential synergy of phytochemicals in cancer prevention: mechanism of action. Journal of Nutrition, v. 134, n.12, p. 0022-3166/04, 2004.

LIU, Z. Chemical methods to evaluate antioxidant ability. Chemical Reviews, v. 110, p. 5675-5691, 2010.

LIU, Y. et al., Food Research International (2018), https://doi.org/10.1016/j.foodres.2018.08.038 
LUNA, C.; ESTÉVEZ, M. Oxidative damage to food and human serum proteins: Radicalmediated oxidation vs. glyco-oxidation. Food Chemistry, v. 267, p. 111-118, 2018.

MARTÍNEZ-NAVARRETE, N.; VIDAL, M. M. C.; LAHUERTA, J. J. M. Los compuestos bioactivos de las frutas y sus efectos en la salud. Actividad dietética, v. 12, n. 2, p. 64-68, 2008.

MOLYNEUX, P. The use of the stable free radical diphenylpicryl-hydrazyl (DPPH) for estimating antioxidant activity. Songklanakarin Journal of Science and Technology, v. 26, n. 2, p. 211-219, 2004.

NERI-NUMA, I. A. et al. Small Brazilian wild fruits: nutrients, bioactive compounds, healthpromotion properties and commercial interest. Food Research International, v. 103, p. 345-360, 2018.

ONIVOGUI, G. et al. Influence of extraction solvents on antioxidant and antimicrobial activities of the pulp and seed of Anisophyllea laurina R. Br. ex Sabine fruits. Asian Pacific Journal of Tropical Biomedicine, v. 6, n. 1, p. 20-25, 2016.

PEREDA, J. A. O. et al. Tecnologia de Alimentos: componentes dos alimentos e processos. Porto Alegre: Artmed. 2005. 294p.

PEREIRA, M. C. Avaliação de compostos bioativos em frutos nativos do Rio Grande do Sul. 2011. 124f. Dissertação de Mestrado. Universidade Federal do Rio Grande do Sul, Porto Alegre, 2011.

PEREIRA, E. S. et al. Psidium cattleianum fruits: a review on its composition and bioactivity. Food Chemistry, v. 258, p. 95-103, 2018.

RE, R. et al. Antioxidant activity applying an improved ABTS radical cation decolorization assay. Free Radical Biology and Medicine, v. 26, p. 1231-1237, 1999.

RIBEIRO, E. P.; SERAVALLI, E. A. G. Química de alimentos. 2. ed. São Paulo: Edgard Bllucher, 2007.

ROGINSKY, V.; LISSI, E. A. Review of methods to determine chain-breaking antioxidant activity in food. Food Chemistry, v. 92, p. 235-254, 2005.

RUFINO, M. S. M. et al. Metodologia científica: determinação da atividade antioxidante total em frutas pela captura do radical livre ABTS. Comunicado Técnico Embrapa, Fortaleza, CE, 2007.

RUFINO, M. S. M. Propriedades funcionais de frutas tropicais brasileiras não tradicionais. 2008. 237 f. Tese (Doutorado em Agronomia), Universidade Federal Rural do Semi- Árido, Mossoró, 2008. 
SÁ, S. et al. Phytochemistry and antimicrobial activity of Campomanesia adamantium. Revista Brasileira de Farmacognosia, v. 28, p. 303-311, 2018.

SCHIASSI, M. C. E. V. et al. Fruits from the Brazilian Cerrado region: Physico-chemical characterization, bioactive compounds, antioxidant activities, and sensory evaluation. Food Chemistry, V. 245, P. 305-311, 2018.

SINGH, B. et al. Phenolic compounds as beneficial phytochemicals in pomegranate (Punica granatum L.) peel: a review. Food Chemistry, v. 261, p. 75-86, 2018.

SINGLETON, V. L.; ORTHOFER, R.; LAMUELA-RAVENTOS, R. M. Analysis of total phenols and other oxidation substrates and antioxidants by means of Folin-Ciocalteu reagent. Methods in Enzymology, v. 299, p. 152-178, 1999.

SINGLETON, V. L.; ROSSI, J. A. Colorimetry of total phenolics with phosphomolybdicphosphotungstic acid reagents. American Journal of Enology and Viticulture, v.16, p.144-158, 1965.

SOUSA, C. M. M. et al. Fenóis totais e atividade antioxidante de cinco plantas medicinais. Química Nova, v. 30, p. 351-355, 2007.

TAIZ, L.; ZEIGERT, E. Fisiologia Vegetal. 3. ed. Porto Alegre: Artmed, 2004. 719 p. TRUEBA, G. P.; SANCHEZ, G. M. Los flavonoides como antioxidantes naturales. Latin American Journal of Pharmacy, v. 20, p. 297-306, 2001.

VUOTTO, M.L. et al. Antimicrobial and antioxidant activities of Feijoa sellowiana fruit. International Journal of Antimicrobial Agents, v.13, p.197-201, 2000.

ZUANAZZI, J. A. S.; MONTANHA, J. A. Flavonoides. In: SIMÕES, C. M. O. et al. Farmacognosia: da planta ao medicamento. 5. ed. Florianópolis: UFSC, p. 577-614, 2004. 